\title{
Seismic Evaluation of Steel Moment Resisting Frames (MRFs) - Supported by Loose Granular Soil
}

\author{
Muhammad Tayyab Naqash, Qazi Umar Farooq, Ouahid Harireche \\ Department of Civil Engineering, Faculty of Engineering, Islamic University of Madinah, Medina, Saudi Arabia \\ Email: tayyab@iu.edu.sa, qaziumar@gmail.com, ouahidharireche@gmail.com
}

How to cite this paper: Naqash, M.T., Farooq, Q.U. and Harireche, O. (2019) Seismic Evaluation of Steel Moment Resisting Frames (MRFs)-Supported by Loose Granular Soil. Open Journal of Earthquake Research, 8, 37-51.

https://doi.org/10.4236/ojer.2019.82003

Received: January 28, 2019

Accepted: March 25, 2019

Published: March 28, 2019

Copyright ( 2019 by author(s) and Scientific Research Publishing Inc. This work is licensed under the Creative Commons Attribution International License (CC BY 4.0).

http://creativecommons.org/licenses/by/4.0/

\begin{abstract}
Soil underneath a structure might affect the behavior and the overall response of the structure in seismic events. The role of loose soil conditions and the inclusion of soil-structure interaction (SSI) in the analysis are important issues that need to be addressed. Since steel structures are light, two configurations designed as spatial and perimeter are considered to study the effect of soil on the steel structural frames for the same building. The paper provides a parametric analysis on the influence of SSI on the overall performance of MRFs (Moment Resisting Frames) according to the provisions of Saudi Building Code (SBC) [1]. A case study has been developed in which spatial and perimeter moment resisting frames of 12, 6 and 3 stories residential buildings are designed using Saudi Building Code (SBC) prescriptions. A modal response spectrum analysis has been carried out to see the influence of SSI on the fundamental period of vibration, top story displacement and inter-story drift limitations. Moreover, a static non-linear analysis has been performed to investigate the performance of frames, thus allowing to identify the influence of SSI on the structural design of steel MRFs.
\end{abstract}

\section{Keywords}

Soil Structure Interaction (SSI), Saudi Building Code (SBC), American Society of Civil Engineers (ASCE), Federal Emergency Management Agency (FEMA), Moment Resisting Frames (MRFs), Seismic Resistance, Seismic Codes

\section{Introduction}

The earth is an internally active planet and therefore the increase and decrease in seismic activity for a certain region is a normal phenomenon. The Hejaz region 
of Saudi-Arabia was usually considered as seismically inactive but the recent earthquake in the region; for example one in Jeddah has raised the concerns. Therefore, it is extremely important to consider seismic effects in the design of modern infrastructure. According to thinkhazard report [2], earthquake hazard in Saudi Arabia is classified as medium. The national center for recording earthquake, reported an earthquake of magnitude 2.5 on the Richter scale at Jan. 16, 2018, 14-kilometers north-west of Madinah, it was very shallow, and the depth was only 7-kilometers. As per USGC (United States Geological Survey), an earthquake of magnitude 5.7 occurred in western Saudi Arabia on 2009-05-19 with coordinates $\left(25.291^{\circ} \mathrm{N}, 37.740^{\circ} \mathrm{E}\right)$ [3] [4]. Therefore, structures located in these regions need to be designed to withstand earthquake action. In some circumstances, the design practice and assumptions involved in seismic design are not always accurate, especially when considering the soil topography due to its unpredictable and changeable behavior with time. Although considerable research has been devoted over the years to the effect of soil structure interaction, there is still controversy regarding the role of SSI in the seismic performance of structures founded on soft soil. The SSI effect can be neglected if the structure is flexible and resting on hard soil such as moment resisting frames constructed on a stiff soil. Therefore, when steel MRFs are designed for hard soil conditions the SSI can be ignored. Nevertheless, the effect of SSI cannot be under estimated if such frames are designed on soft soil. Traditionally it is believed that SSI is beneficial to the seismic response. However, in most design codes, SSI effects are not clearly emphasized. For example, referring to Eurocode 8 [5], soft soil conditions are accounted for solely by introducing a soil factor parameter in the design spectrum. In design practice, neglecting SSI effects is believed to be a conservative assumption that would simplify analyse and at the same time lead to improved safety margins. However, the fulfilment of the damageability criteria (inter-story drifts) would be difficult to achieve as the structure flexibility will be higher for higher fundamental periods. To this end, satisfying drift limitations will enhance the member profiles drastically, especially beam sections, compared to column profiles, which will disturb the capacity design rules of the code or otherwise will lead to uneconomical design solutions. Furthermore, the use of high ductility will not be possible as the ductility demand required by the design cannot be achieved. As per Eurocode 8 [6], the following conditions are believed to have strong influence and therefore need to be incorporated in the design: 1) Structure where second order effects play a dominant role 2) Structures with massive or deep-seated foundations, such as bridge piers, offshore caissons and silos 3) Slender tall structures, such as towers and chimneys 4) Structures supported on very soft soils, with average shear wave velocity less than $100 \mathrm{~m} / \mathrm{s}$, such as clayey soils.

Many researches are devoted to the analysis of structures with SSI. Minasidis et al. [7] investigated the effects of soil-structure interaction on the inelastic response of two-dimensional steel frames subjected to near-fault earthquakes using response spectrum analysis from a read earthquake accelerogram. Karavasilis 
et al. [8] proposed an alternative procedure to estimate the maximum inelastic roof displacement and the maximum inelastic Interstory drift ratio along the height of regular multi-story steel moment resisting frames (MRFs) subjected to pulse-like ground motions based on dimensional response analysis. Malhotra in [9] presented interpretation of the response characteristics of three recorded and one synthetic near-field ground motions and showed that pulse-like ground motions with high peak ground velocity over peak ground acceleration ratio (PGV/PGA) have wide acceleration-sensitive region in their elastic response spectrum. Farouk et al. [10] examined the effect of the superstructure's rigidity on the contact stress and the differential settlement for plane 2-bay frames. Christopoulos et al. [11] found that the effect of the vertical accelerations of near-fault records on the demand in rotational ductility and on the maximum story deflections of steel moment-resisting frames is negligible, even though a large increase in the maximum axial loads of columns is noted. Makris and Chang [12] found that, although in several occasions near-fault records resemble cycloidal pulses, the response of structures with low to moderate periods is substantially affected by the high-frequency fluctuations that often override the long duration pulse. MacRae et al. [13] found that inelastic demands of medium and longer period oscillators responding to near-fault strike-normal shaking increased for sites close to the fault as the distance along the fault from the epicenter increased. Rao and Jangid [14], examining sliding systems under near-fault motions found that the resultant sliding base displacement is mainly due to the normal component of the near-fault motion. Mavroeidis and Papageorgiou [15] proposed a simple, yet effective, analytical model for the representation of near-field strong ground motions.

In the present study, the flexible foundation effect is considered to check the influence of SSI on the performance of MRFs. The formulations for springs constraints at the ground surface were used based on FEMA 356 [16] [17]. G is the effective modal mass for the fundamental mode of vibration in the direction under consideration computed to be $20.35 \mathrm{Mpa}$. In the current case the foundation is considered as rigid rectangular with length (L) equals $3 \mathrm{~m}$ and breadth (B) equals $2 \mathrm{~m}$. The embedment depth of the foundation is placed at $3 \mathrm{~m}$. Geotechnical conditions of Al-Madinah region of Saudi Arabia are used in this study. The soil type was selected based on geotechnical investigation report conducted for the construction of one of the academic blocks at the Islamic University of Madinah. The field investigations were carried out in July 2009. The soil strata under consideration are layered, the top $9 \mathrm{~m}$ thick layer comprises brown Clayey Sand. The denser underlying layer from $9.0 \mathrm{~m}$ to the explored depth of $15 \mathrm{~m}$ includes gravels. The groundwater table and the bed rock were not intercepted during exploration. Geometric properties of the foundations imply that the influence zone of the structure transpires only in the top layer of the soil. Based on field and laboratory investigations the soil properties at loose state were adopted (i.e. Relative density Dr. $=30 \%)$. The soil parameters used in this study are shown in Table 1 and the calculated stiffnesses are shown in Table 2 [18] [19] [20]. 
Table 1. Adopted soil parameters.

\begin{tabular}{cc}
\hline Soil Parameter & Values \\
\hline Classification & Medium Plastic Clayey Sand (SC) \\
Maximum Unit weight $\left(\gamma_{\mu a \xi}\right)$ & $17.26 \mathrm{kN} / \mathrm{m}^{3}\left(1759.43 \mathrm{~kg} / \mathrm{m}^{3}\right)$ \\
Maximum Unit weight $\left(\gamma_{\text {min }}\right)$ & $14.77 \mathrm{kN} / \mathrm{m}^{3}\left(1505.60 \mathrm{~kg} / \mathrm{m}^{3}\right)$ \\
Adopted relative density $($ Dr. $\%)$ & $30 \%$ \\
Used Unit weight $(\gamma)$ & $15.44 \mathrm{kN} / \mathrm{m}^{3}\left(1574.62 \mathrm{~kg} / \mathrm{m}^{3}\right)$ \\
Shear wave velocity for loose sand $(\mathrm{Vs})$ & $175 \mathrm{~m} / \mathrm{s}$ \\
Poisson's Ratio $(v)$ for loose sand & 0.25 \\
Shear modulus for the soils $\left(G_{O}=\rho\right.$ Vs $\left.{ }^{2}\right)$ & $48.22 \mathrm{Mpa}$ \\
The effective modal mass $(G)$ & $20.35 \mathrm{Mpa}$ \\
\hline
\end{tabular}

Table 2. Static stiffness (N/mm) for the adopted soil properties.

\begin{tabular}{ccc}
\hline Direction & Symbol & Static Stiffness (N/mm) \\
\hline Horizontal Translation along $\mathrm{x}$ & $\mathrm{Kx}$ & 130827.3 \\
Horizontal Translation along $\mathrm{y}$ & $\mathrm{Ky}$ & 135478.8 \\
Vertical Translation along $\mathrm{z}$ & $\mathrm{Kz}$ & 157420.8 \\
Rocking about $\mathrm{x}$ & $\mathrm{Kxx}$ & $1.52 \mathrm{E}+11$ \\
Rocking about $\mathrm{y}$ & $\mathrm{Kyy}$ & $2.77 \mathrm{E}+11$ \\
Rocking about $\mathrm{z}$ & $\mathrm{Kzz}$ & $3.16 \mathrm{E}+11$ \\
\hline
\end{tabular}

\section{Parametric Study}

\subsection{General}

To investigate the effect of SSI on spatial and perimeter moment resisting frames according to SBC, a case study is conducted on 12, 6 and 3 stories residential building. The building has a rectangular plan measuring $33.0 \mathrm{~m}$ by $19.8 \mathrm{~m}$ in longitudinal and transversal direction, respectively. Spatial and perimeter frames hereafter are named as " $S$ " and " $P$ ", respectively. The typical floor plan of the building with the indication of spatial and perimeter frame is shown in Figure 1 (a), whereas, the elevation of 6 stories frame with the masses calculated from the loads is given in Figure 1(b), the outer columns are named as "coll" and the inner columns as "col".

In the case of 12 story frame configuration, the columns are designed considering four blocks each one of 3 stores; for 6 stores the column are designed considering three blocks each one including two stories whereas for 3 stories building a single block is used. The inter-story height of each story is $3.5 \mathrm{~m}$ and therefore the overall height for 12, 6 and 3 story buildings are $42.0 \mathrm{~m}, 21.0 \mathrm{~m}$ and $10.5 \mathrm{~m}$, respectively. 


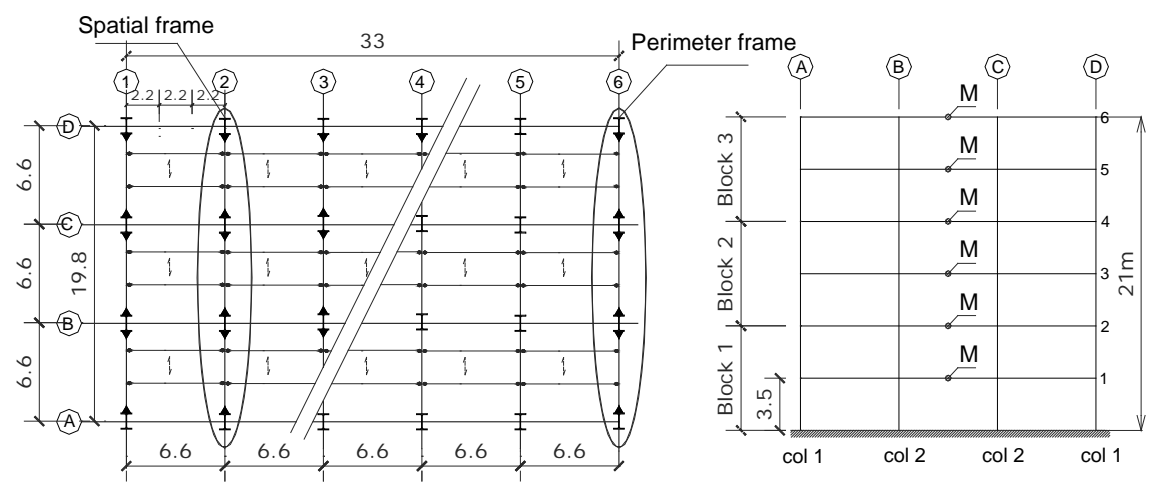

mass (single storey) $=85$ and $212 \mathrm{KN}-\mathrm{sec}^{2} / \mathrm{m}$ for spatial and perimeter frame respectively using SBC

(a)

(b)

Figure 1. Typical floor plan of the building (a) and Frame elevation for 6 stories only (b).

\subsection{Design Criteria}

Vertical loads acting on the structure are evaluated providing as a result a total gravity loading (structural and non-structural) equal to $6.0 \mathrm{kN} / \mathrm{m}^{2}$, with an imposed load of $2.0 \mathrm{kN} / \mathrm{m}^{2}$. The secondary beams are simply supported, spaced at $2.2 \mathrm{~m} \mathrm{C} / \mathrm{C}$ and oriented along the longitudinal direction of the building. The masses at each floor level for spatial and perimeter frames are 85 and 212 $\mathrm{kN}-\mathrm{sec}^{2} / \mathrm{m}$ respectively. The primary beams are designed to satisfy both the ultimate and serviceability limit states using steel grade S-275.

The reference frames are designed using importance factor 1.0 and considering soil class D with $S_{s}$ and $S_{1}$ as $1.07 \mathrm{~g}$ and $0.57 \mathrm{~g}$, respectively (See Figure 2). A seismic category for the structure is considered as $D$ from $S_{D S}(0.713)$ and $S_{D 1}$ $(0.38)$ with the assumed site class. In total, 12 cases are analyzed as shown in Table 3 [21] [22] [23] [24].

Table 4 shows the primary and secondary beams for spatial and perimeter frames whereas in Table 5 column profiles for all the cases are mentioned.

\section{Design Results}

A linear modal dynamic analysis is developed for the seismic design of the frames. The fundamental period obtained from the codified formulation for 12 , 6 and 3 stories are found to be $1.44 \mathrm{sec}, 0.83 \mathrm{sec}$ and $0.47 \mathrm{sec}$, respectively, which is lower than the one obtained by modal analysis (See Table 6); in this circumstance the code specifies that scaling factors for the design forces and drift must be applied. Both scaling factors (forces and drifts) are $85 \%$ of the ratio of "the static base shear ( $V_{\text {static }}$ " to "the modal base shear $\left(V_{b}\right)$ ".

Table 6 shows the fundamental period (See Figure 3) and top displacement (See Figure 4) of all the frames with SSI and without SSI. It is obvious that the fundamental period of vibration and the top displacement are higher when SSI was considered.

The simplified formulae given by seismic codes tend to underestimate the fundamental period of vibration, they are being based on empirical evaluation, 
therefore globally accounting also for the stiffening effects of non-structural elements e.g. partition walls and infills etc. These effects are obviously of major importance for steel frames which exhibit relatively low horizontal stiffness. The underestimation of the natural period (considering only short branch of spectrum) leads to conservative design assumptions e.g. higher design acceleration (consequently high seismic base shear) and in turn larger inter-story drifts.

From Figure 3 and Figure 4 it is evident that SSI influences the overall stiffness of low, medium and high rise MRFs. Although in this case a medium soil was considered under a moderate seismic event. Nevertheless, the effect of SSI can even be more worsen for cases when structures are in high seismicity zones and with more weak and flexible soil which needs to be further investigated.

The Interstory drift limitations were still satisfied for 3 story spatial and perimeter frames (See Figure 5).

The drift limitations for perimeter frames both for 6 stories (See Figure 6) and 12 stories (See Figure 7) were not satisfied for some stories when SSI was considered. This is further to be noted that the SBC limits are still relaxed $(0.02 \mathrm{~h})$ for satisfying the Interstory drifts as with some codes like Eurocode these limits are quite strict $(0.005 \mathrm{~h}, 0.0075 \mathrm{~h}$ and $0.01 \mathrm{~h})$. A comparative study will be useful to see the pros and cons of Eurocode 8 on SCB. Drift checks: $0.02 \mathrm{~h}=0.02 \times 3500=$ $70 \mathrm{~mm}$ limiting value.

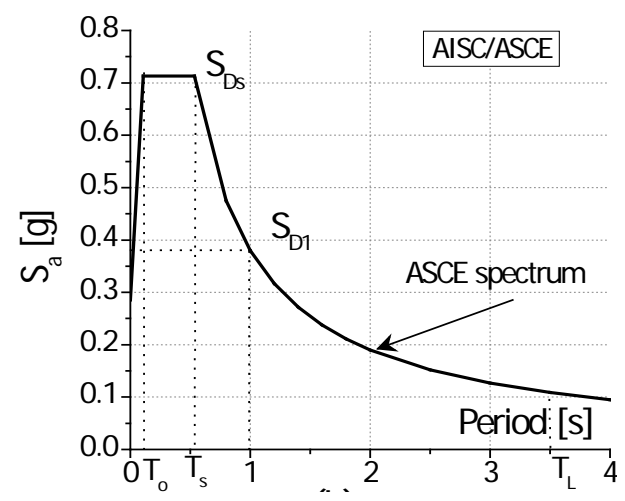

Figure 2. Response spectra.

Comparison of Fundamental Period for Spatial and Perimeter Frames with and without SSI

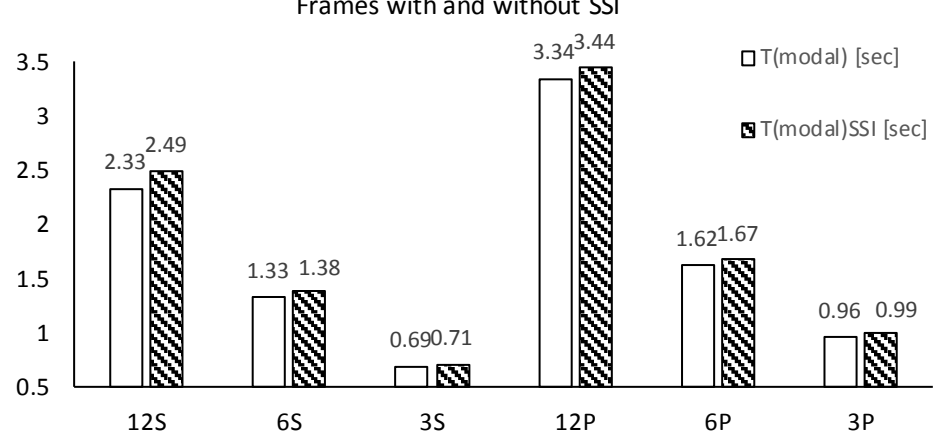

Figure 3. Comparisons of fundamental period of vibrations for spatial and perimeter frames. 
Comparison of Top displacements for Spatial and Perimeter

Frames with and without SSI

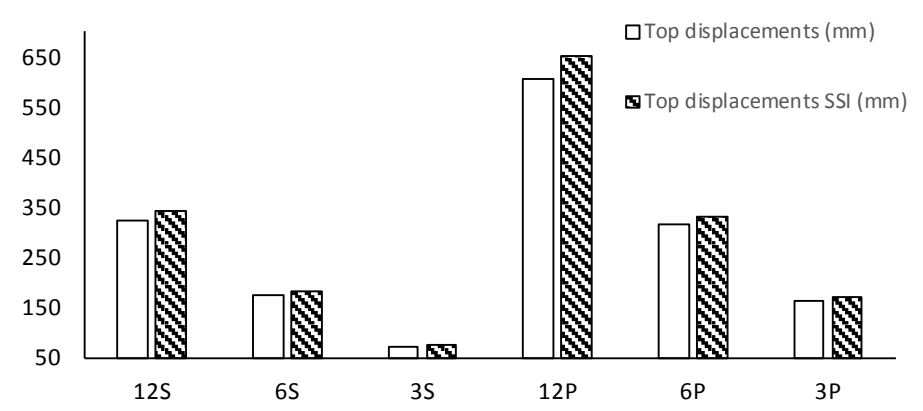

Figure 4. Comparisons of top displacement for spatial and perimeter frames.

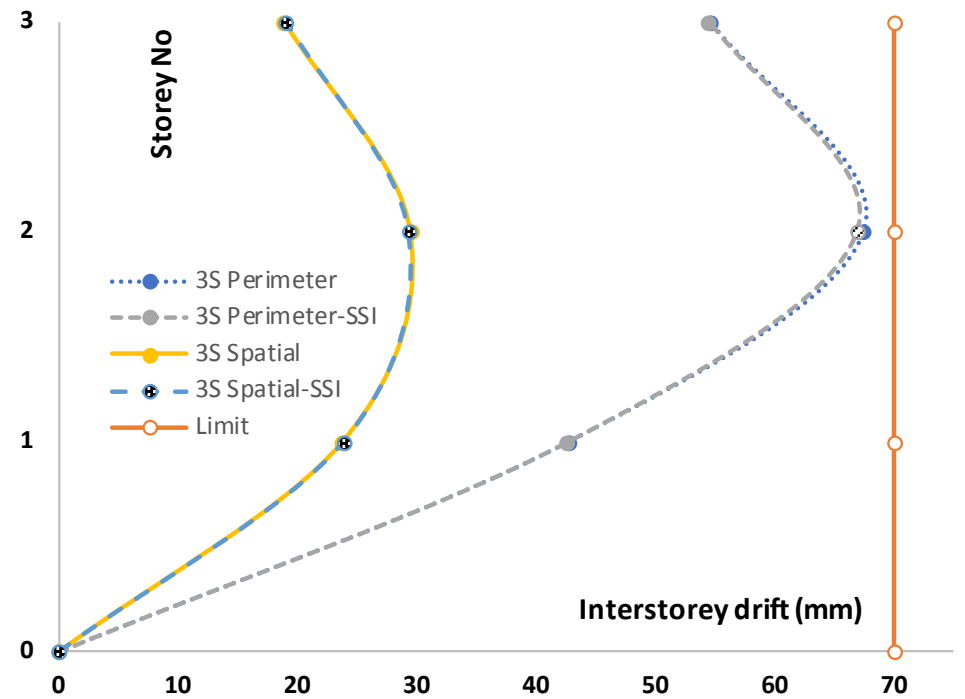

Figure 5. Interstory drift curves for 3 story perimeter and spatial frame with and without SSI.

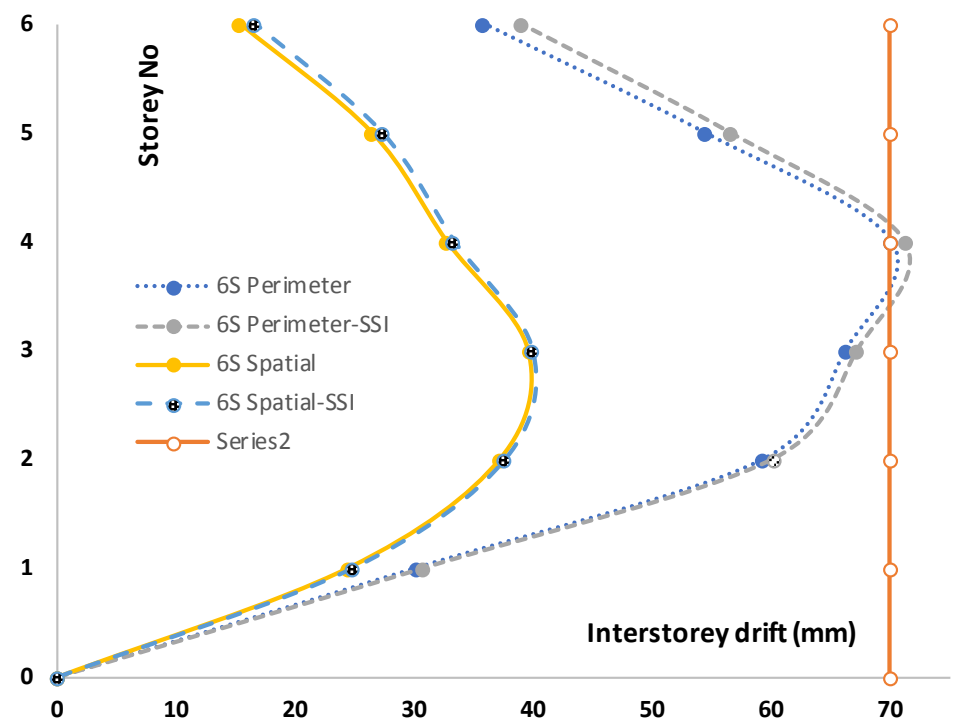

Figure 6. Interstory drift curves for 6 story perimeter and spatial frame with and without SSI. 


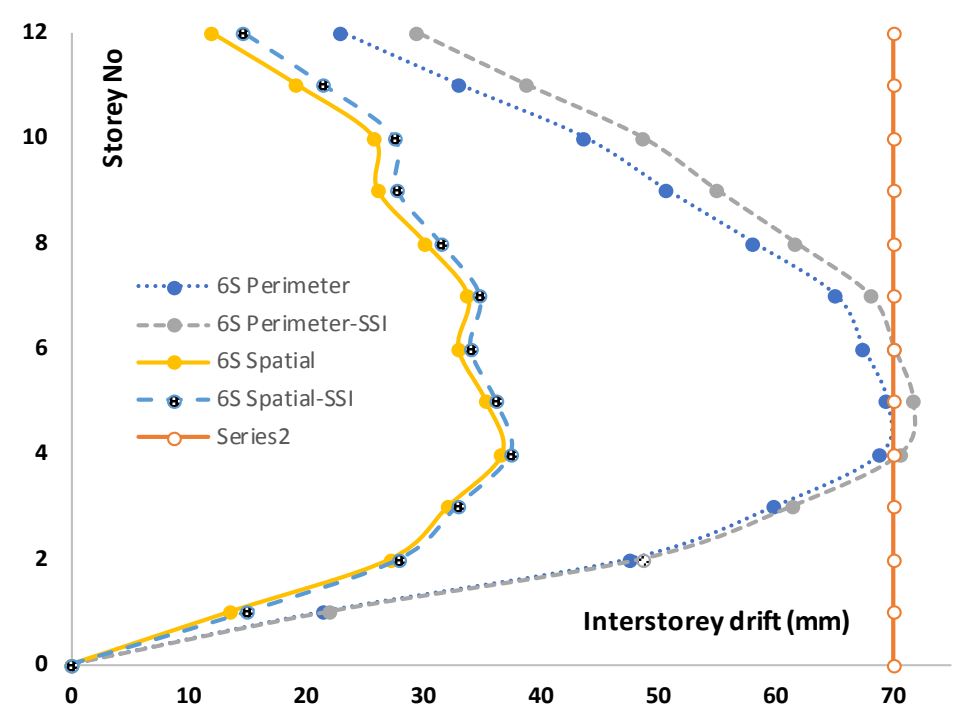

Figure 7. Interstory drift curves for 12 story perimeter and spatial frame with and without SSI.

Table 3. All analyzed cases.

\begin{tabular}{cccc}
\hline Case No & Fixed Base & Case & SSI \\
\hline 1 & 12-Stories-Spatial frame with SMF & 7 & 12-Stories-Spatial frame with SMF \\
2 & 12-Stories_-Perimeter frame with SMF & 8 & 12-Stories-Perimeter frame with SMF \\
3 & 6-Stories-Spatial frame with SMF & 9 & 6-Stories-Spatial frame with SMF \\
4 & 6-Stories-Perimeter frame with SMF & 10 & 6-Stories-Perimeter frame with SMF \\
5 & 3-Stories-Spatial frame with SMF & 11 & 3-Stories-Spatial frame with SMF \\
6 & 3-Stories-Perimeter frame with SMF & 12 & 3-Stories-Perimeter frame with SMF \\
\hline
\end{tabular}

Table 4. Obtained primary beams profiles for spatial and perimeter frames.

\begin{tabular}{|c|c|c|c|}
\hline & & Spatial & Perimeter \\
\hline Ductility & Stories & Sections & Sections \\
\hline SMF & $1-3$ & IPE500 & IPE450 \\
\hline SMF & $1-6$ & & IPE500 \\
\hline SMF & $1-12$ & & IPE500 \\
\hline
\end{tabular}

Table 5. The obtained column profiles.

\begin{tabular}{ccccc}
\hline Stories & Col & Block & Perimeter & Spatial \\
\hline & & 1 & HE1000M & HE550B \\
& 1 & 2 & HE800B & HE450B \\
12 & 3 & HE650B & HE400B \\
& 4 & HE550B & HE280B \\
& 1 & HE1000M & HE800M \\
& 2 & HE800B & HE450M \\
\hline
\end{tabular}




\begin{tabular}{|c|c|c|c|c|}
\hline & & 3 & HE650B & HE300M \\
\hline & & 4 & HE550B & $\mathrm{HE} 280 \mathrm{M}^{\mathrm{SCWB}}$ \\
\hline \multirow{6}{*}{6} & \multirow{3}{*}{1} & 1 & HE650M & HE400B \\
\hline & & 2 & HE550B & HE340B \\
\hline & & 3 & HE450A & HE300A \\
\hline & \multirow{3}{*}{2} & 1 & HE700M & HE400M \\
\hline & & 2 & HE600B & $\mathrm{HE} 280 \mathrm{M}^{\mathrm{SCWB}}$ \\
\hline & & 3 & HE600A & $\mathrm{HE} 280 \mathrm{M}^{\mathrm{SCWB}}$ \\
\hline \multirow[b]{2}{*}{3} & 1 & \multirow[b]{2}{*}{1} & HE400M & HE $360 \mathrm{~B}^{\text {SCWB }}$ \\
\hline & 2 & & HE400M & HE $360 \mathrm{~B}^{\mathrm{SCWB}}$ \\
\hline
\end{tabular}

SCWB: Strong Column Weak Beam.

Table 6. Fundamental period of vibrations and top displacements.

\begin{tabular}{cccccc}
\hline Type & Stories & $\begin{array}{c}\mathrm{T} \text { (modal) } \\
{[\mathrm{sec}]}\end{array}$ & $\begin{array}{c}\mathrm{T} \text { (modal) } \\
\text { SSI } \\
{[\mathrm{sec}]}\end{array}$ & $\begin{array}{c}\text { Top displacements } \\
(\mathrm{mm})\end{array}$ & $\begin{array}{c}\text { Top } \\
\text { displacements } \\
\text { SSI (mm) }\end{array}$ \\
\hline \multirow{3}{*}{ Spatial } & 12 & 2.33 & 2.49 & 324 & 343 \\
& 6 & 1.33 & 1.38 & 175 & 181 \\
& 3 & 0.69 & 0.71 & 165 & 169 \\
& 12 & 3.34 & 3.44 & 608 & 653 \\
Perimeter & 6 & 1.62 & 1.67 & 315 & 331 \\
& 3 & 0.96 & 0.99 & 72 & 74 \\
\hline
\end{tabular}

\section{Non-Linear Analysis}

To check the lateral load resisting performance of the frames, static pushover analysis has been carried out using FEMA-350 recommendations [25]. Triangular distribution (unit load at roof level) of static incremental loads (continues from the gravity load case) has been applied and the displacement at the roof level has been controlled. Mechanical non-linearities of the members have been assumed to be concentrated in plastic hinges at the ends [26].

The formation of plastic hinges based on FEMA 356 rules are introduced as input in SAP 2000 program [26].

The FEMA 356 [27] rules with the IO, LS and CP limit states for hinge rotation have been used in the analysis with the SAP 2000 program. The five points $(\mathrm{O}, \mathrm{B}, \mathrm{C}, \mathrm{D}$ and $\mathrm{E})$ as shown in Figure 8 are used to define the hinge rotation behaviour of analysed frame members according to FEMA recommendations. Three more points Immediate Occupancy (IO), Life Safety (LS) and (Collapse Prevention) $\mathrm{CP}$ are used to define the acceptance criteria for the hinge. The colours below show different acceptance criteria. 


\begin{tabular}{ccccccc}
\hline B & IO & LS & CP & C & D & E \\
\hline \multirow{2}{*}{ Basic } & $\begin{array}{c}\text { Intermediate } \\
\text { Occupancy }\end{array}$ & $\begin{array}{c}\text { Life } \\
\text { Safety }\end{array}$ & $\begin{array}{c}\text { Collapse } \\
\text { Prevention }\end{array}$ & & Collapse & \\
\hline
\end{tabular}

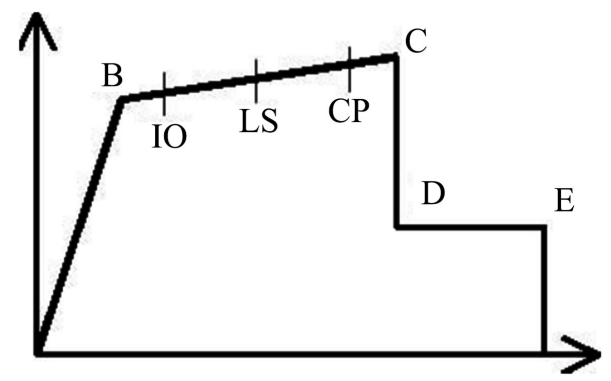

Figure 8. Load versus displacement and target performance levels as per FEMA 356.

The performance is shown in Figure 9, Figure 10 and Figure 11 for 3 stories, 6 stories and 12 stories respectively. The obtained structural capacity curves are plotted in Figure 12, Figure 13 and Figure 14 for 3 stories, 6 stories and 12 stories respectively that shows total base shear $\left(V_{b}\right)$ versus top displacement $(\Delta)$. All these curves show reduced stiffness of the frames when SSI was considered.

In the case of 3 story frames (spatial and perimeter) plastic hinges were formed at the top and bottom of almost all columns having reached the collapse limit state (See Figure 9(a), Figure 9(b), Figure 9(c) and Figure 9(d)). In the case of 6 stories spatial frames (See Figure 10(a), Figure 10(b), figure) plastic hinges were formed at the bottom four floors and the columns reached to the collapse prevention limit state in the case of SSI whereas it reached to collapse limit state with fixed base condition. The 6 stories perimeter frames (See Figure $10(\mathrm{c})$, Figure 10(d)) reached to collapse limit state and in general plastic hinges were formed along all stories.

Finally, for 12 stories spatial frames (Figure 11(a) and Figure 11(b)) plastic hinges were formed at the bottom eight floors and the columns reached to the collapse prevention limit state in the case of SSI whereas it reached to collapse limit state with fixed base condition. The 12 stories perimeter frames (Figure 11(c) and Figure 11(d)) reached to collapse prevention limit state (SSI) and to collapse limit state (fixed base) and in general plastic hinges were formed along ten stories.

\section{Conclusions}

Comparison is made in terms of fundamental period of vibration, inter-story drifts and performance for 3, 6 and 12 story frames with and without SSI. These were designed as spatial and perimeter MRFs with a response modification factor of 8 using Saudi Building Codes. In total 12 cases were conducted to see the effect of SSI on such frames. Frames supported on loose granular soil (Site Class D) with moderate seismic zone, compatible to the PGA like Madinah region were considered. The results revealed the following: 


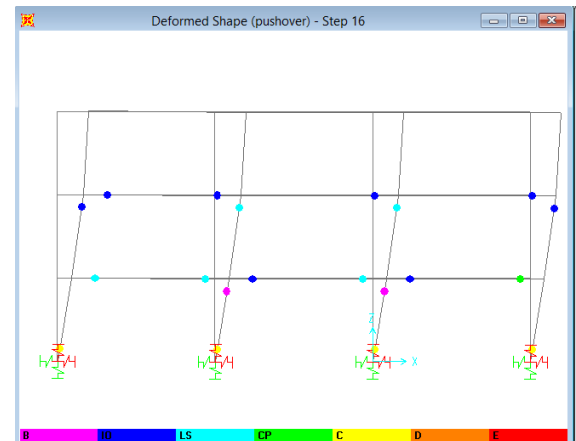

(a) Collapse

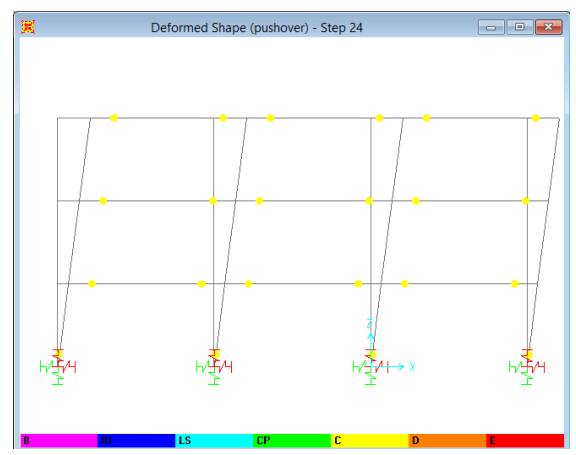

(c) Collapse

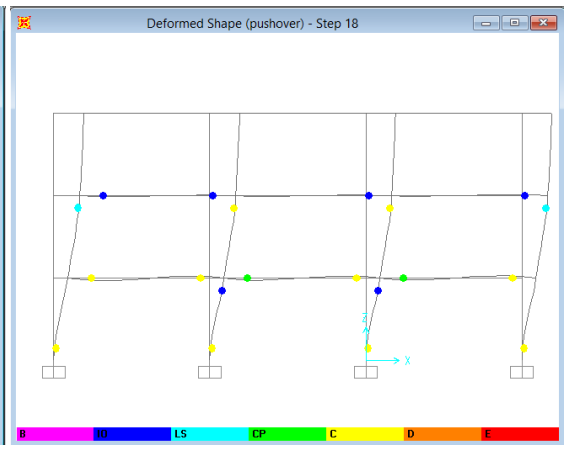

(b) Collapse

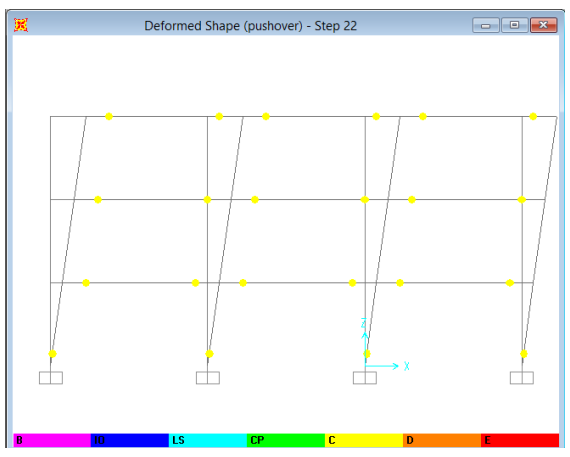

(d) Collapse

Figure 9. Performance of 3 stores: (a) (with SSI-spatial), (b) (without SSI-spatial), (c) (with SSI-perimeter) and (d) (without SSI-perimeter).

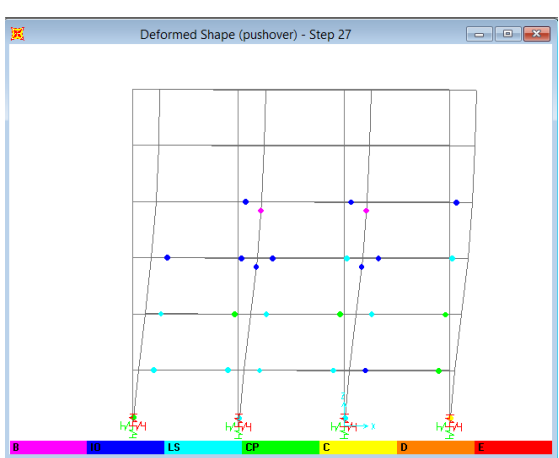

(a) Collapse Prevention

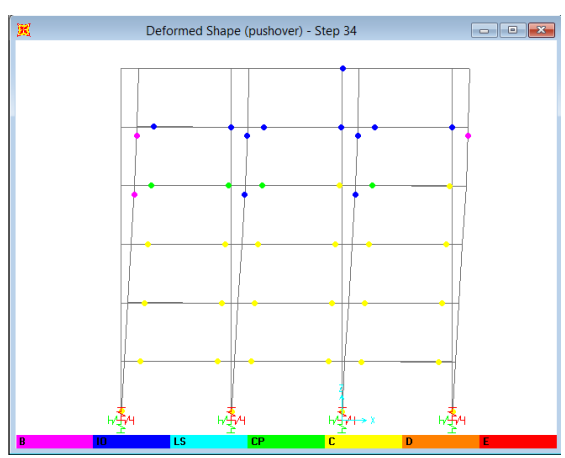

(c) Collapse

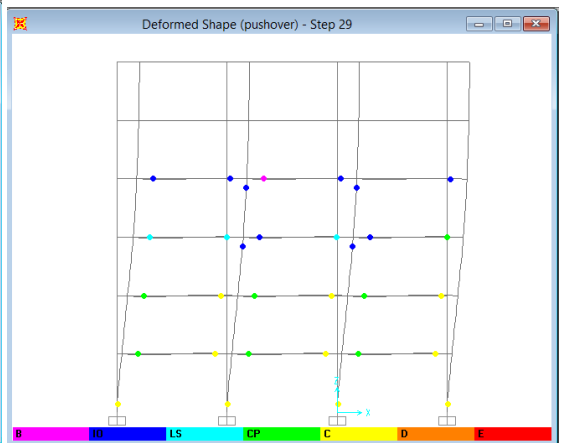

(b) Collapse

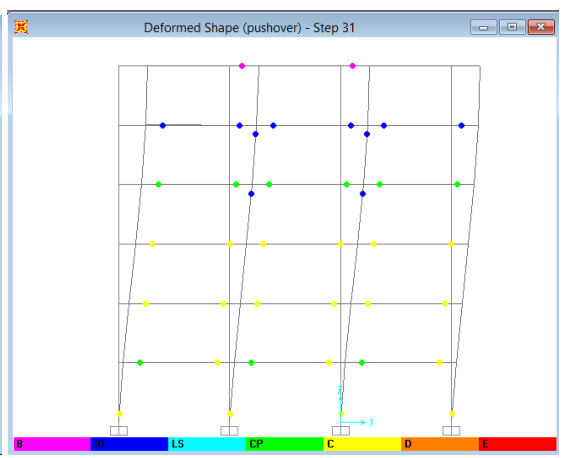

(d) Collapse

Figure 10. Performance of 6 stories: (a) (with SSI-spatial), (b) (without SSI-spatial), (c) (with SSI-perimeter) and (d) (without SSI-perimeter). 


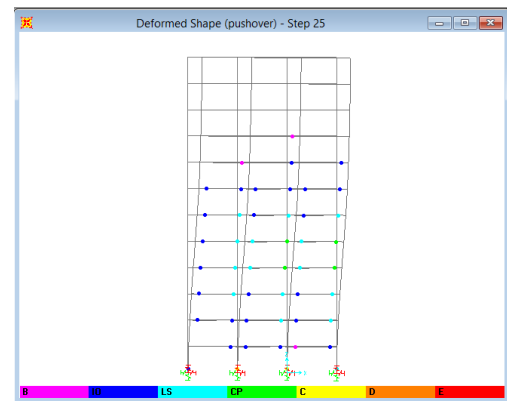

(a) Collapse Prevention

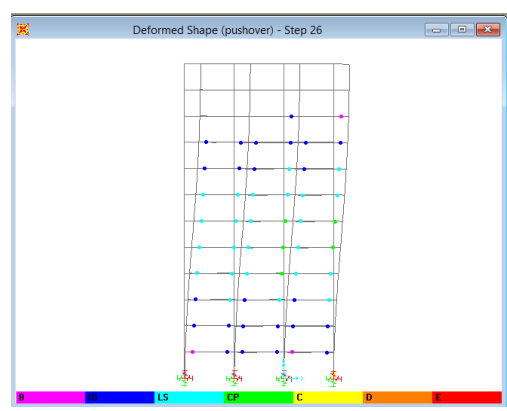

(c) Collapse Prevention

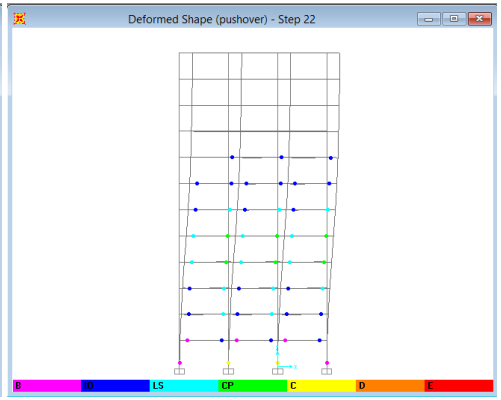

(b) Collapse

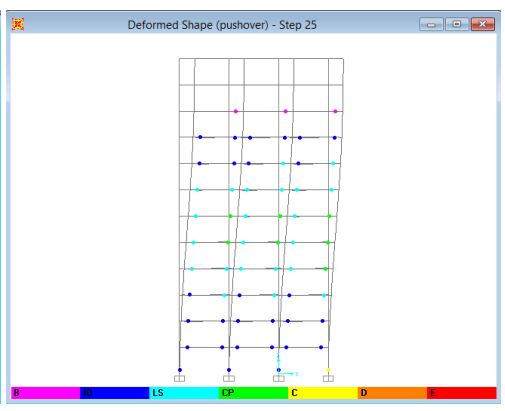

(d) Collapse

Figure 11. Performance of 12 stories: (a) (with SSI-spatial), (b) (without SSI-spatial), (c) (with SSI-perimeter) and (d) (without SSI-perimeter).

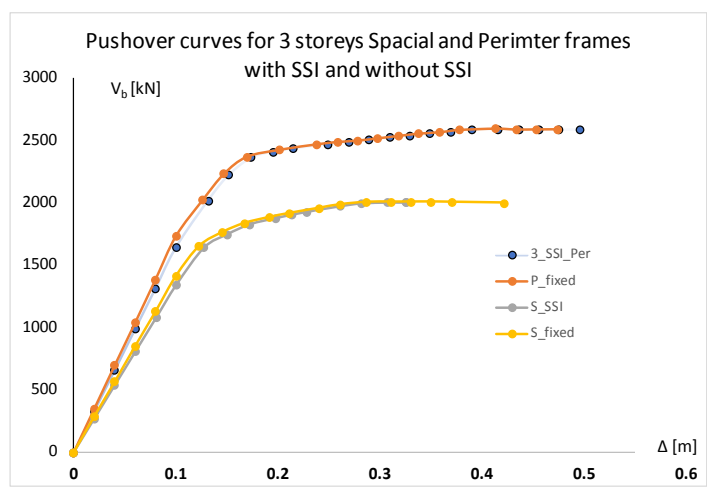

Figure 12. Pushover curves for 3 story perimeter and spatial frame with and without SSI.

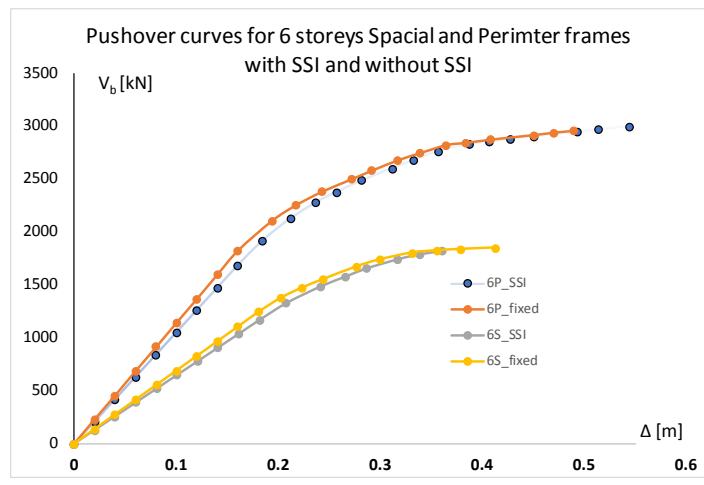

Figure 13. Pushover curves for $\mathrm{f} 6$ story perimeter and spatial frame with and without SSI. 


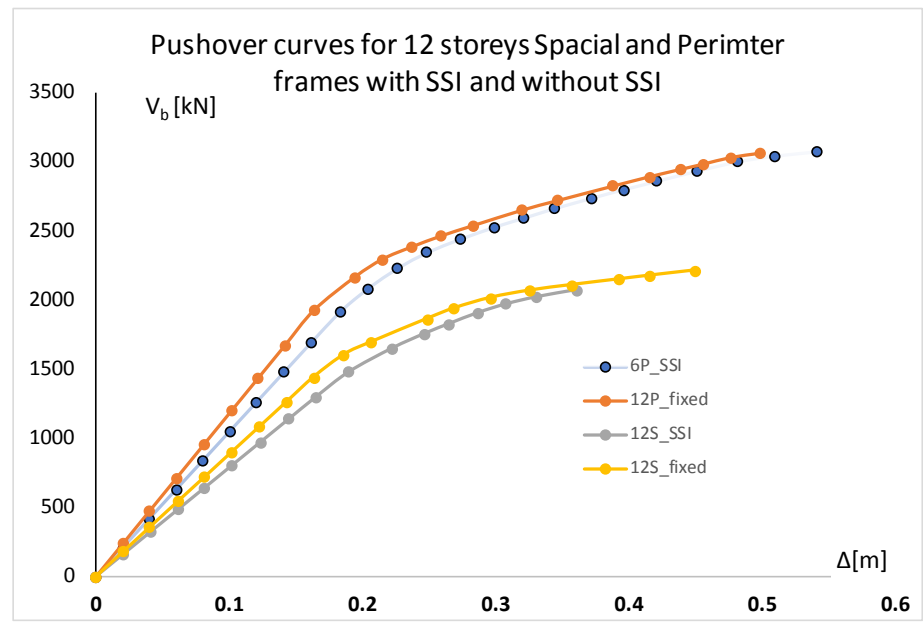

Figure 14. Pushover curves for 12 story perimeter and spatial frame with and without SSI.

- In the case of loose granular soil with moderate seismicity, SSI affects fundamental period of vibration and top building displacement.

- The Interstory drifts for spatial frames were within the limits as these are generally less loaded as compared to perimeter frames. On the other hand, the Interstory drifts for 6 and 12 stories were exceeding the limits in the case of perimeter frames.

- Spatial frames were less affected by considering SSI compared to perimeter frames, which concludes that if frames are subjected to high seismic force the influence of SSI becomes more critical and needs to be incorporated in the design.

- Overall the stiffness and ductility of the frames decreased when SSI was considered; this might be due to the capacity design approach which needs to be further investigated.

- The collapse limit state was reached in the case of 3 story spatial and perimeter frames for both cases. For 6 and 12 stories (spatial and perimeter frames) collapse prevention limit state was observed for the cases when SSI was considered, and collapse limit state was reached when SSI was not considered.

A more detailed study might be useful to see the effect of SSI under more stringent cases such as, heavily loaded steel frames (braced) etc., considering loose/soft ground.

\section{Acknowledgements}

This work was supported by Deanship of Research at the Islamic University of Madinah with research project No 83/40.

\section{Conflicts of Interest}

The authors declare no conflicts of interest regarding the publication of this paper. 


\section{References}

[1] Saudi Building Code (2007) SBC 301 Loads \& Forces Requirements. Saudi Building Code National Committee, Riyadh.

[2] thinkhazard. http://thinkhazard.org/en/report/215-saudi-arabia/EQ

[3] S. G. Survey. https://www.sgs.org.sa/English/NaturalHazards/Pages/Earthquakes.aspx

[4] USGS. M5.7-Western Saudi Arabia.

[5] EN-1998-3 (2005) Eurocode 8, Design of Structures for Earthquake Resistance, Part 3: Assessment and Retrofitting of Buildings. European Committee for Standardization, CEN, 36 B-1050, Brussels.

[6] EN-1998-1 (2005) Eurocode 8, Design of Structures for Earthquake Resistance, Part 1: General Rules, Seismic Actions and Rules for Buildings. European Committee for Standardization, CEN, 36 B-1050, Brussels.

[7] Minasidis, G., Hatzigeorgiou, G. and Beskos, D. (2014) SSI in Steel Frames Subjected to Near-Fault Earthquakes. Soil Dynamics and Earthquake Engineering, 66, 56-68. https://doi.org/10.1016/j.soildyn.2014.06.030

[8] Karavasilis, T.L., Makris, N., Bazeos, N. and Beskos, D.E. (2010) Dimensional Response Analysis of Multistory Regular Steel MRF Subjected to Pulselike Earthquake Ground Motions. Journal of Structural Engineering, 136, 921-932. https://doi.org/10.1061/(ASCE)ST.1943-541X.0000193

[9] Malhotra, P.K. (1999) Response of Buildings to Near-Field Pulse-Like Ground Motions. Earthquake Engineering \& Structural Dynamics, 28, 1309-1326. https://doi.org/10.1002/(SICI)1096-9845(199911)28:11<1309::AID-EQE868>3.0.CO ;2-U

[10] Farouk, H. and Farouk, M. (2014) Soil, Foundation, and Superstructure Interaction for Plane Two-Bay Frames. International Journal of Geomechanics, 16, B4014003. https://doi.org/10.1061/(ASCE)GM.1943-5622.0000453

[11] Christopoulos, C., Filiatrault, A. and Léger, P. (1999) Effects of Near-Fault Vertical Seismic Accelerations on the Response of Steel Moment-Resisting Frames. Proceedings of 8 th Canadian Conference on Earthquake Engineering, 293-298.

[12] Makris, N. and Chang, S.-P. (2000) Response of Damped Oscillators to Cycloidal Pulses. Journal of Engineering Mechanics, 126, 123-131. https://doi.org/10.1061/(ASCE)0733-9399(2000)126:2(123)

[13] MacRae, G.A., Morrow, D.V. and Roeder, C.W. (2001) Near-Fault Ground Motion Effects on Simple Structures. Journal of Structural Engineering, 127, 996-1004. https://doi.org/10.1061/(ASCE)0733-9445(2001)127:9(996)

[14] Rao, P.B. and Jangid, R. (2001) Performance of Sliding Systems under Near-Fault Motions. Nuclear Engineering and Design, 203, 259-272. https://doi.org/10.1016/S0029-5493(00)00344-7

[15] Mavroeidis, G.P. and Papageorgiou, A.S. (2003) A Mathematical Representation of Near-Fault Ground Motions. Bulletin of the Seismological Society of America, 93, 1099-1131. https://doi.org/10.1785/0120020100

[16] FEMA-356 (2000) Commentary for the Seismic Rehabilitation of Buildings, FEMA-356. Federal Emergency Management Agency, Washington DC.

[17] ANSI/AISC-360-10 (2010) Specification for Structural Steel Buildings. American Institute of Steel Construction, Chicago, IL.

[18] Naqash, M.T. (2016) Effect of Interstorey Drift Limits on High Ductility in Seismic 
Design of Steel Moment Resisting Frames. Pakistan Journal of Engineering and Applied Sciences, 16, 133-142.

[19] Naqash, M.T. (2017) Codal Comparisons for the Seismic Resistance of Steel Moment Resisting Frames (MRF). Part A: Codes Approach. International Journal of Construction Engineering and Management, 6, 254-263.

[20] Naqash, M.T. and Alluqmani, A. (2018) Codal Requirements Using Capacity Design Philosophy, and Their Applications in the Design of Steel Structures in Seismic Zones. Open Journal of Earthquake Research, 7, 88-107. https://doi.org/10.4236/ojer.2018.72006

[21] Naqash, M.T. (2014) Study on the Fundamental Period of Vibration of Steel Moment Resisting Frames. International Journal of Advanced Structures and Geotechnical Engineering, 3, 1-6.

[22] Naqash, M.T. (2012) Optimum Design of Steel Moment Resisting Frames Using Eurocode 8. Doctorate Ph.D. Thesis, Department of Engineering and Geology, University of Chiete and Pescara, Pescara.

[23] Naqash, M.T., De Matteis, G. and De Luca, A. (2012) Seismic Design of Steel Moment Resisting Frames-European versus American Practice. NED University Journal of Research, 9, 45-60.

[24] Naqash, M.T. and Umar, F.Q. (2018) Performance Of Rigid Steel Frames Under Adequate Soil Conditions Using Seismic Code Provisions in Open Journal of Civil Engineering (OJCE). Open Journal of Civil Engineering (OJCE), 8, 1-12.

[25] P. FEMA-350 (2000) Recommended Seismic Design Criteria for New Steel Moment-Frame Buildings FEMA-350. FEMA-350, Rich Mond, Calif, Washington DC.

[26] CSI SAP V15 (2002) Integrated Finite Element Analysis and Design of Structures Basic Analysis Reference Manual. Computers and Structures, Inc., Berkeley, CA.

[27] P. FEMA-356 (2000) Commentary for the Seismic Rehabilitation of Buildings, FEMA-356. Federal Emergency Management Agency, Washington DC. 